\title{
Pancreatic $\beta$-cells express hepcidin, an iron-uptake regulatory peptide
}

\author{
Hasan Kulaksiz, Evelyn Fein ${ }^{1}$, Peter Redecker ${ }^{2}$, Wolfgang Stremmel ${ }^{1}$, Guido Adler and Yalcin Cetin ${ }^{3}$ \\ Division of Gastroenterology, Department of Internal Medicine, University Hospital Ulm, Robert-Koch-Street 8, D-89081 Ulm, Germany \\ ${ }^{1}$ Division of Gastroenterology, Department of Internal Medicine, University Hospital Heidelberg, D-69120 Heidelberg, Germany \\ ${ }^{2}$ Department of Cell Biology, Hannover Medical School, Center of Anatomy, D-30625 Hannover, Germany \\ ${ }^{3}$ Department of Molecular Cell Biology, Institute of Anatomy and Cell Biology, Philipps-University Marburg, D-35033 Marburg, Germany \\ (Correspondence should be addressed to H Kulaksiz; Email: hasan.kulaksiz@uniklinik-ulm.de)
}

\begin{abstract}
Body iron is involved in various vital functions. Its uptake in the intestine is regulated by hepcidin, a bioactive peptide originally identified in plasma and urine and subsequently in the liver. In the present study, we provide evidence at the transcriptional and translational levels that hepcidin is also expressed in the pancreas of rat and man. Immunohistochemical studies localized the peptide exclusively to $\beta$-cells of the islets of Langerhans. Immunoelectron microscopical analyses revealed that hepcidin is confined to the insulin-storing $\beta$-cell secretory granules. As demonstrated in insulinoma-derived RINm5F cells, the

expression of hepcidin in $\beta$-cells is regulated by iron. Based on the present findings we conclude that pancreatic islets are an additional source of the peptide hepcidin. The localization of this peptide to $\beta$-cells suggests that pancreatic $\beta$-cells may be involved in iron metabolism in addition to their genuine function in blood glucose regulation. In view of the various linked iron/glucose disorders in the pancreas, the present findings may provide an insight into the phenomenology of intriguing mutual relationships between iron and glucose metabolisms.

Journal of Endocrinology (2008) 197, 241-249
\end{abstract}

\section{Introduction}

Iron is an essential component of hemoglobin and myoglobin and of many enzymes involved in redox reactions and energy metabolism. Low levels of iron in the circulation may cause severe dysfunctions (e.g., anemia, hypoxia) while iron overload may be toxic because of its ability to generate reactive oxygen species. Thus, blood iron concentration is finely regulated. Since humans and other mammals lack effective mechanisms to excrete excess iron, the regulation of absorption of dietary iron, which happens predominantly in the proximal intestine, is the only way of maintaining iron balance. Excessive dietary iron uptake may cause iron deposition in many vital organs, including the liver, heart, skin, and especially pancreas leading to diabetes mellitus that is found in hereditary hemochromatosis, a group of genetic disorders characterized by the dysregulation of iron absorption (Pietrangelo 2004, Beutler 2006).

Hence, iron homeostasis by adequate regulation of iron uptake is of particular importance. In this respect, the small peptide hepcidin proved to function as the key regulator of iron metabolism. Hepcidin was isolated as a 25 -amino acid peptide in human plasma and urine, exhibiting antimicrobial activity (Krause et al. 2000, Pigeon et al. 2001). Ongoing studies hitherto discovered the peptide mainly in the liver (Krause et al. 2000, Pigeon et al. 2001, Kulaksiz et al. 2004, Pietrangelo 2004, Beutler 2006). Animal and cell culture studies could demonstrate that hepcidin acts as a negative regulator of iron absorption in the small intestine and of iron release from macrophages
(Hentze et al. 2004, Ganz 2005). Secondary iron overload induced a higher expression of hepcidin in the liver (Pigeon et al. 2001, Montosi et al. 2005). Recent studies demonstrated an abnormal low hepcidin expression and disrupted hepcidin regulation in most types of hemochromatosis (Bridle et al. 2003, Muckenthaler et al. 2003, Kulaksiz et al. 2004, Pietrangelo 2004, Beutler 2006) and the association of hepcidin mutations with severe juvenile hemochromatosis (Roetto et al. 2003).

It has been repeatedly reported that iron influences glucose metabolism, which in turn affects iron metabolic pathways (Fernandez-Real et al. 2002a). Likewise, body iron stores are positively correlated with serum insulin and blood glucose concentrations (Tuomainen et al. 1997).

Inspired by these observations we analyzed in the present study the existence of the iron-regulatory peptide hepcidin in the human pancreas at the transcriptional and translational levels as well as its cellular and subcellular localization and regulation by iron. The findings will show that the endocrine pancreas is an additional source of hepcidin; its co-localization with insulin in $\beta$-cells is discussed perspectively.

\section{Materials and Methods}

\section{Tissues and tissue preparation}

Adult male Wistar rats ( $n=6$, body weight of $250-300 \mathrm{~g}$ ) were used for the light and electron microscopic investigations. The principles of laboratory animal care and specific national 
laws were followed. Rats were killed by decapitation under carbon dioxide anesthesia. The dissected tissue specimens were then quenched in isopentane precooled with liquid nitrogen, freeze-dried for $48 \mathrm{~h}$ and fixed by vapor-phase paraformaldehyde (Kulaksiz et al. 2002). Surgical specimens of non-diseased pancreatic regions from patients (three females, five males, age range $34-79)$ suffering from insulinoma $(n=3)$ or glucagonoma $(n=3)$ or from ductal adenocarcinoma $(n=2)$ were treated in the same way. In addition, normal pancreatic tissue samples $(n=3)$ were obtained through an organ donor program when no suitable recipient for pancreas transplantation was found. Healthy human liver samples $(n=7)$ were obtained after hemi-hepatectomy in adult patients with liver metastases. Pancreatic tissue from a female, 54-year-old patient with hemochromatosis homozygous for the C282Y mutation was resected during autopsy. After liver transplantation, she died due to multiorgan failure.

The investigations were approved by the local ethical committee. All animal experiments described here were conducted in accordance with the accepted standards of human animal care. Investigations with human tissues described here were conducted in accordance with the guidelines in the Declaration of Helsinki.

\section{Peptide synthesis, immunization procedure, and antibodies}

From the published pro-hepcidin sequence (Krause et al. 2000, Pigeon et al. 2001) the peptides hepcidin (28-47) and hepcidin (70-84) were synthesized as C-terminal amides using a standard Fmoc protocol (Kulaksiz et al. 2002). The peptides were coupled to a keyhole limpet hemocyanin using $m$-maleimidobenzoyl$N$-hydroxysuccinimide ester, and two specific pathogen free (SPF) rabbits (Charles River, Sulfzfeld, Germany Iffa Credo) were immunized with each peptide conjugate (Eurogentec, Seraing, Belgium). After testing the titer by ELISA, the antisera EG(1)-HepC, EG(2)-HepC, each directed against hepcidin (70-84) and EG(1)-HepN, and EG(2)-HepN, each directed against hepcidin (28-47) (Kulaksiz et al. 2004, 2005), were used in the present study. The peptide epitopes used for the generation of the antibodies displayed no homology with any hitherto reported protein except hepcidin as confirmed by the BLAST P2 search. Human and rat hepcidin show a sequence homology of $88 \%$ why the antisera against human hepcidin could be successfully employed in the rat pancreas.

\section{Cell culture}

RINm5F, rat insulinoma cells, were grown in RPMI 1640 medium (PAA, Pasching, Austria) containing L-glutamine, supplemented with $10 \%$ (vol/vol) heat-inactivated fetal calf serum, penicillin (100 units $/ \mathrm{ml})$, and streptomycin $(100 \mu \mathrm{g} / \mathrm{ml})$. The cells were cultivated at $37^{\circ} \mathrm{C}$ in $5 \% \mathrm{CO}_{2}$. They were incubated with increasing concentrations of Fe-NTA from $1 \mu \mathrm{M}$ up to $65 \mu \mathrm{M}$ for $72 \mathrm{~h}(n=10)$ according to a previously published protocol (Gehrke et al. 2003). After stimulation experiments, total RNA or proteins were extracted from RINm5F cells and analyzed by quantitative PCR and immunoblot assays.

The human hepatoma HepG2 cells were obtained from the German Collection of Microorganisms and Cell Culture (Braunschweig, Germany) and grown at $37^{\circ} \mathrm{C}$ in $5 \% \mathrm{CO}_{2}$ in RPMI 1640 media (Gibco) supplemented with 10\% (vol/vol) heat-inactivated FBS, penicillin (100 units/ml), and streptomycin $(100 \mu \mathrm{g} / \mathrm{ml})$. These cells were used as control.

\section{Expression analyses in pancreas and RINm $5 \mathrm{~F}$ cells}

RNA isolation was performed using the Qiagen RNAeasy kit including DNase digestion $(n=15)$. Reverse transcription (RT)-PCR analysis was performed as described previously (Kulaksiz et al. 2004, 2005) using the following primers and specifications given in $5^{\prime}-3^{\prime}$ orientation: human hepcidin (GenBank database accession no. NM021175) - 5'-CCT GAC CAG TGG CTC TGT TT- $3^{\prime}$ and $5^{\prime}$-GGT TCT ACG TCT TGC AGC AC-3', corresponding to positions 130-149 and 330-311 and rat hepcidin (GenBank database accession no. NM053469) - 5'-GGC AGA AAG CAA GAC TGA TGA C-3' and 5'-ACA GGA ATA AAT AAT GGG GCG-3', corresponding to positions 146-168 and 346-332. Rat ferroportin (GenBank database accession no. AF394785) - 5'-GCT AGA ATC GGT CTT TGG TCC- $3^{\prime}$ and $5^{\prime}$-ACC ATG ATG AAA TGC AGA AGG-3'; corresponding to positions 1646-1666 and 1765-1745.

After an initial denaturation of $94^{\circ} \mathrm{C}$ for $4 \mathrm{~min}$, the reactions were subjected to 30 cycles of the following thermal program: $94^{\circ} \mathrm{C}$ for $30 \mathrm{~s}, 60^{\circ} \mathrm{C}$ for $30 \mathrm{~s}$, and $72{ }^{\circ} \mathrm{C}$ for $30 \mathrm{~s}$; this program was followed by a final 5 min elongation step at $72{ }^{\circ} \mathrm{C}$. The amplification products were run on an ethidium bromide-stained $1 \cdot 8 \%$ of $89 \mathrm{mM}$ Tris $/ 89 \mathrm{mM}$ boric acid/2 mM EDTA ( $\mathrm{pH} 8 \cdot 3$ ) agarose gel. To exclude possible genomic DNA contamination, control samples were employed in which the reverse transcriptase enzyme was omitted from the cDNA synthesis reaction. As specificity controls, the amplified PCR products were sequenced on a 377 DNA sequencer (Perkin-Elmer). The sequence analyses revealed that the PCR-generated products have a complete homology with the cDNAs of the corresponding proteins.

\section{Quantitative RT-PCR}

Real-time quantification of mRNA transcripts was performed according to the protocol published (Gehrke et al. 2003; $n=10$ ). In brief, a two-step RT-PCR was performed using the LightCycler system and Relative Quantification Software Version 1.0 (Roche). In the first step, cDNA synthesis was performed using the First Strand cDNA Synthesis Kit for RT-PCR (Roche) according to the manufacturer's instructions. In a second step, transcripts of hepcidin were amplified in duplicate with specific sense and antisense primers. All transcripts were detected using SYBR green I according to the manufacturer's instructions and were normalized to $\beta$-actin as the internal control. 


\section{Immunohistochemistry}

After embedding the specimens in epoxy resin (Araldite), serial semithin sections were cut at $0.5 \mu \mathrm{m}$ and processed for immunohistochemical staining. Details on the antibodies used for the detection of pancreatic hormones (insulin, glucagon, somatostatin, and pancreatic polypeptide) have been published earlier (Cetin et al. 1993).

Immunostainings according to the avidin-biotin-peroxidase complex (ABC) technique and method controls were performed as outlined previously (Cetin et al. 1993, Kulaksiz et al. 2002, 2005). Briefly, the ABC method included incubation of semithin sections with primary antibodies (1:2000) in PBS containing $0 \cdot 1 \%$ Triton X-100 (v/v) for $24 \mathrm{~h}$ at $4{ }^{\circ} \mathrm{C}$, followed by incubation for $30 \mathrm{~min}$ at room temperature with the second antibody, biotin-labeled goat anti-rabbit IgG (Jackson Immuno Research, West Grove, USA). The sections were then incubated for $30 \mathrm{~min}$ with a preformed complex of biotin-peroxidase/ streptavidin (Jackson Immuno Research), and the peroxidase activity was revealed using $0 \cdot 02 \%$ diaminobenzidine hydrochloride $(\mathrm{w} / \mathrm{v})$ with $0 \cdot 3 \%$ nickel sulfate $(\mathrm{w} / \mathrm{v})$ as the chromogen. The specificity of the antibodies was tested by preincubation of all antibodies with homologous and heterologous antigens according to previously published protocols (Kulaksiz et al. 2002, 2004, 2005). The preadsorption of hepcidin antibodies with the homologous antigens (hepcidin (28-47) or hepcidin (70-84)) at concentrations as low as $6.25 \mu \mathrm{g} / \mathrm{ml}$ completely blocked immunostaining in the pancreas as well as in the reference organ liver. Preadsorption of the antibodies with heterologous antigens and with insulin, limpet hemocyanin (both from Sigma) at concentrations up to $100 \mu \mathrm{g} / \mathrm{ml}$ had no effect on immunostaining.

\section{Electron microscopy}

For immunogold electron microscopy, anesthetized rats were transcardially perfused with prewash and fixative solutions. Briefly, the fixative consisted of a mixture of $4 \%(\mathrm{v} / \mathrm{v})$ depolymerized paraformaldehyde, $0 \cdot 1 \%$ glutaraldehyde, and $0.2 \%$ picric acid in $0.1 \mathrm{M}$ phosphate buffer $(\mathrm{pH} 7 \cdot 4)$ containing $0.5 \mathrm{mM}$ calcium chloride. Following fixation of the dissected tissue in the same fixative, the specimens were embedded either in Epon or in Unicryl (British BioCell, Cardiff, UK), as described previously (Cetin et al. 1993). Surgical specimens of normal pancreatic tissue obtained from patients suffering from glucagonoma or nesidioblastosis were fixed in a mixture of cacodylate-buffered $2 \%$ paraformaldehyde and $2 \cdot 5 \%$ glutaraldehyde or in cacodylate-buffered $1.4 \%$ glutaraldehyde, and subsequently embedded in Epon. On-grid labeling of thin sections was performed as outlined elsewhere (Cetin et al. 1993) using secondary antibodies conjugated with 10 or $12 \mathrm{~nm}$ colloidal gold (British BioCell; Jackson Immuno Research). Images of micrographs were digitalized and their contrast and brightness were adjusted using Adobe Photoshop software.

\section{Immunofluorescence microscopy}

RINm5F cells were grown on cover slides, fixed in cold methanol, and incubated with hepcidin antibodies at a dilution of $1: 1000$ overnight at $4{ }^{\circ} \mathrm{C}$ (Kulaksiz et al. 2004). After washing in PBS ( $\mathrm{pH} 7 \cdot 0$ ), the cells were incubated with an anti-rabbit antibody (diluted 1:200) labeled with Cy3 (Dianova, Hamburg, Germany). The nucleus of the cells was stained using PBS containing $10 \mu \mathrm{g} / \mathrm{ml}$ of $4^{\prime}, 6$-diamidino-2phenylindole (Sigma).

Immunostaining was investigated using an Olympus AX70 microscope. Micrographs were taken using a digital camera (colorview 12, soft imaging system SIS, Münster, Germany) and analySIS software (SIS, Münster, Germany).

\section{Immunoblot analysis}

For western blot analysis $(n=10)$, the protein extracts were incubated for $7 \mathrm{~min}$ at $94{ }^{\circ} \mathrm{C}$ in sample buffer with $4 \%$ (w/v) SDS (Merck), 50 mM Tris- $\mathrm{HCl}$ (pH 8.45), 1 mM EDTA, 3.24 mM dithiothreitol (Roth, Karlsruhe, Germany), 12.5\% (w/v) glycerol (Merck), and 0.002\% bromophenol blue (Merck). To detect hepcidin, a $16 \cdot 5 \%$ tricine-SDS-polyacrylamide gel was used according to the published protocols (Kulaksiz et al. 2002, 2004, 2005). The immunoreaction on the western blot was specifically blocked after preincubation of the antibodies with the corresponding peptide immunogens. The cross-reactivity with the second goat anti-rabbit antibody was excluded by appropriate controls (Kulaksiz et al. 2002, 2004, 2005).

\section{Hepcidin measurement by ELISA}

Hepcidin was measured in the supernatants of RINm5F cells by ELISA (DRG Instruments GmbH, Marburg, Germany) according to the published protocol (Kulaksiz et al. 2004, 2005).

\section{Statistical analysis}

Statistical analysis of quantitative variables was performed using the non-parametric Mann-Whitney test. $P<0 \cdot 05$ was considered significant. All statistical analyses were performed using SAS, version 9.1 (SAS Institute, Cary, NJ, USA).

\section{Results}

\section{Expression of hepcidin in the human and rat pancreas}

RT-PCR analyses using specific primers revealed that hepcidin is highly expressed in human and rat pancreas (Fig. 1). The amplification yielded an expected transcript of $201 \mathrm{bp}$. Sequence analyses of the amplification products confirmed a complete homology with the hepcidin cDNAs of rat and man (Krause et al. 2000, Pigeon et al. 2001). As determined by quantitative RT-PCR, the expression of hepcidin in the pancreas was considerable but not as high as 

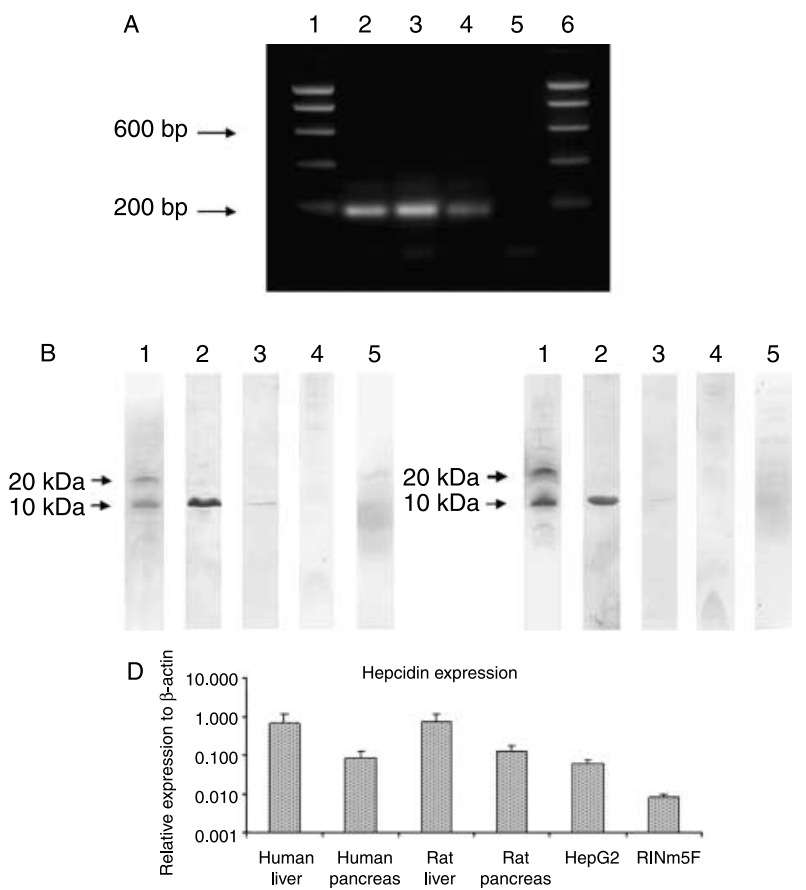

Figure 1 Expression of hepcidin in the pancreas. (A) RT-PCR analysis of human pancreas (lane 2), rat pancreas (lane 3), RIN m5F cells (lane 4), and control of pancreas lacking reverse transcription (lane 5). A bp DNA ladder has been indicated (lanes 1 and 6). (B and C) Immunoblot analysis of hepcidin in the extracts of human liver (lane 1), human (lane 2), and rat (lane 3) pancreas. Note the immunoreactive peptide bands at $10 \mathrm{kDa}$ obtained with both $\mathrm{N}$ - and C-terminal antibodies $\mathrm{EG}(2)-\mathrm{HepN}(\mathrm{B})$ and EG(2)-HepC (C). Note that no immunoreactive peptides are observed in the human pancreatic extracts with preimmunesera (lane 4) or after preincubation of the antibodies with the corresponding peptide immunogens (lane 5). (D) Quantitative RT-PCR $(n=6)$. The expression levels of hepcidin (means) are given as the amount relative to the expression of the housekeeping gene actin in each sample.

that in the liver (Fig. 1). In this respect, it has to be noted that in contrast to the liver the islets of Langerhans of the pancreas, where hepcidin is expressed (see below), constitute merely a small portion of the total pancreatic parenchyma. The existence of hepcidin at the translational level was verified by immunoblotting analyses in human and rat pancreatic extracts. Both $\mathrm{N}$ - and C-terminal region-specific hepcidin antisera concurrently identified the immunoreactive peptide of $\sim 10 \mathrm{kDa}$ (Fig. 1). The size of this pancreatic peptide co-migrating with the immunoreactive band observed in homogenates of the liver (positive control) corresponds to the molecular mass of hepcidin deduced from the respective cDNA sequence (Pigeon et al. 2001, Kulaksiz et al. 2004).

\section{Hepcidin is localized to pancreatic $\beta$-cells}

All hepcidin antisera under study coincidently immunostained distinct cells within the human Langerhans islets, which, by their typical location within the islets and by co-localization with insulin, were clearly identified as $\beta$-cells (Figs 2 and 3 ). Other endocrine cell types (i.e., glucagon $\alpha$, somatostatin $\delta$, and pancreatic polypeptide PP-cells) or the exocrine gland cells were completely unreactive for hepcidin. The same cellular distributive pattern was found in the rat pancreas where a strong hepcidin immunoreactivity was detected in the $\beta$-cells (Fig. 4).

At the subcellular level, hepcidin was confined to the typical secretory granules of the $\beta$-cells, where insulin is
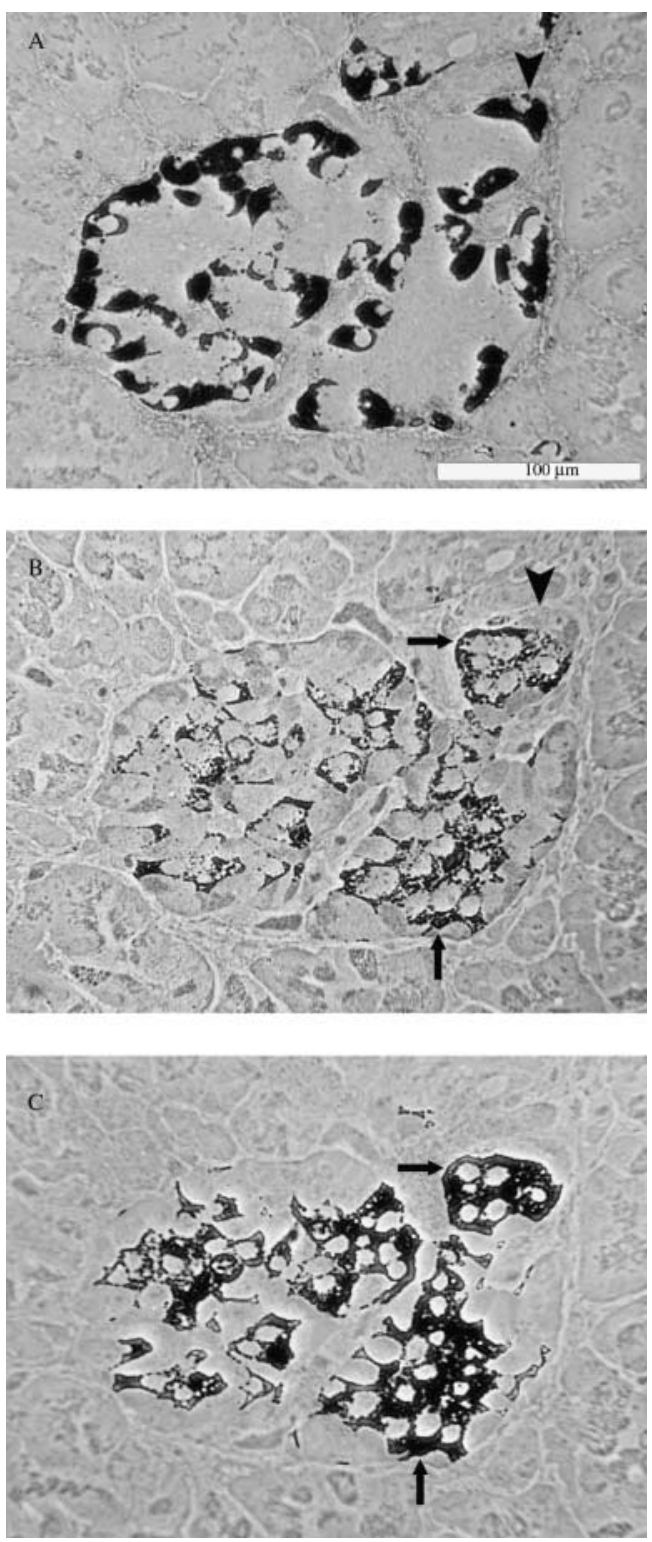

Figure 2 Cellular and subcellular localization of hepcidin in the pancreas. Three serial semithin $(0.5 \mu \mathrm{m})$ sections through an islet of Langerhans in the human pancreas immunostained for (A) glucagon, (B) hepcidin, and (C) insulin. In the pancreatic islet, hepcidin immunoreactivity is exclusively localized to insulin ( $\beta$-) cells (arrows). No immunoreactivity is found in glucagon $(\alpha)$ cells (arrowheads). Scale bar, $100 \mu \mathrm{m}$. 

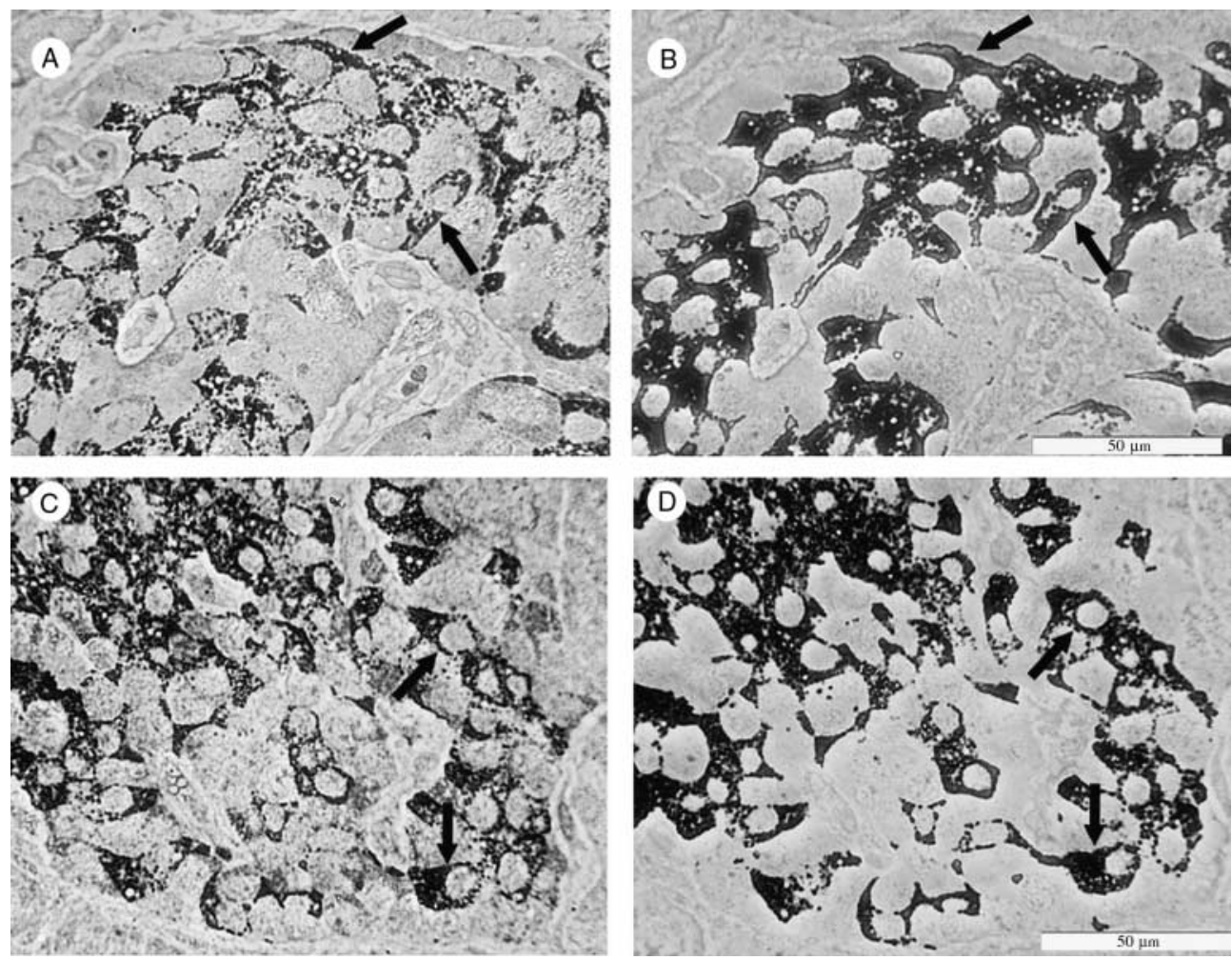

Figure 3 Granular immunoreactivity pattern for hepcidin is shown with $\mathrm{N}$ - and C-terminal hepcidin antisera ((A) EG(2)-HepN and (C) EG(2)-HepC) in serial semithin sections in pancreatic insulin $\beta$-cells (B and D) (arrows). Within the pancreatic islet, hepcidin and insulin are co-localized in the same cells. Scale bars, $50 \mu \mathrm{m}$.

localized (Fig. 5). Hepcidin immunoreactivity exhibited a distinct intragranular topology; the immunoreactivity of this peptide was absent in the electron-lucent halo but was confined to the dense core of the $\beta$-cell secretory granules, i.e. the compartment where insulin is also resident.

\section{Hepcidin expression in $\beta$-cells is regulated by iron}

RINm5F cells, rat insulinoma cells of the pancreas, exhibiting preserved $\beta$-cell features represent a suitable model for $\beta$-cell experiments (Gazdar et al. 1980). RT-PCR analyses using the appropriate primer specifications and combinations successfully employed in the rat liver and pancreas identified the expression of hepcidin in RINm5F cells (Fig. 1). In analogy to the human and rat pancreas, the amplification product in RINm $5 \mathrm{~F}$ cells was also of $201 \mathrm{bp}$, which after sequencing revealed a complete homology to the rat hepcidin cDNA (Pigeon et al. 2001). The existence of the respective translated proteins in these cells was verified by immunocytochemistry and immunoblotting experiments using the region-specific hepcidin antisera (Figs 6 and 7).

The regulation of hepcidin expression in RINm5F cells was analyzed upon exposure to iron, since iron regulates hepcidin expression in the liver (Gehrke et al. 2003, Pietrangelo 2004, Beutler 2006). The regulatory effect of iron on hepcidin gene expression was measured in these cells under various Fe-NTA concentrations using quantitative RT-PCR. Under small amounts of iron, i.e., $1 \mu \mathrm{M}$ up to $10 \mu \mathrm{M}$, a significant up-regulation of hepcidin-mRNA up to threefold was observed in RINm5F cells (Fig. 7), as is also the case in the liver. Remarkably, hepcidin expression was downregulated when Fe-NTA concentrations of $65 \mu \mathrm{M}$ or higher were used, even if the concentrations of Fe-NTA were not cytotoxic as shown in a neutral red assay (Fig. 7). These results were confirmed by immunoblot analyses (Fig. 7).

\section{Discussion}

The present findings show that hepcidin is expressed in the pancreas of rat and man. RT-PCR analyses with specific primers yielded the expected transcripts, which after sequencing revealed complete homology with the corresponding human and rat cDNAs. In immunoblot experiments, the presence of the peptide in the pancreas was verified by two region-specific hepcidin antisera that identified the peptide of a correct molecular mass of $\sim 10 \mathrm{kDa}$ in the pancreas as well as in the reference organ liver. Hence, these data stress the pancreas as an additional source of the peptide hepcidin that hitherto is known to originate mainly from the liver. However, as revealed by the quantitative RT-PCR analyses, the expression rate of hepcidin 

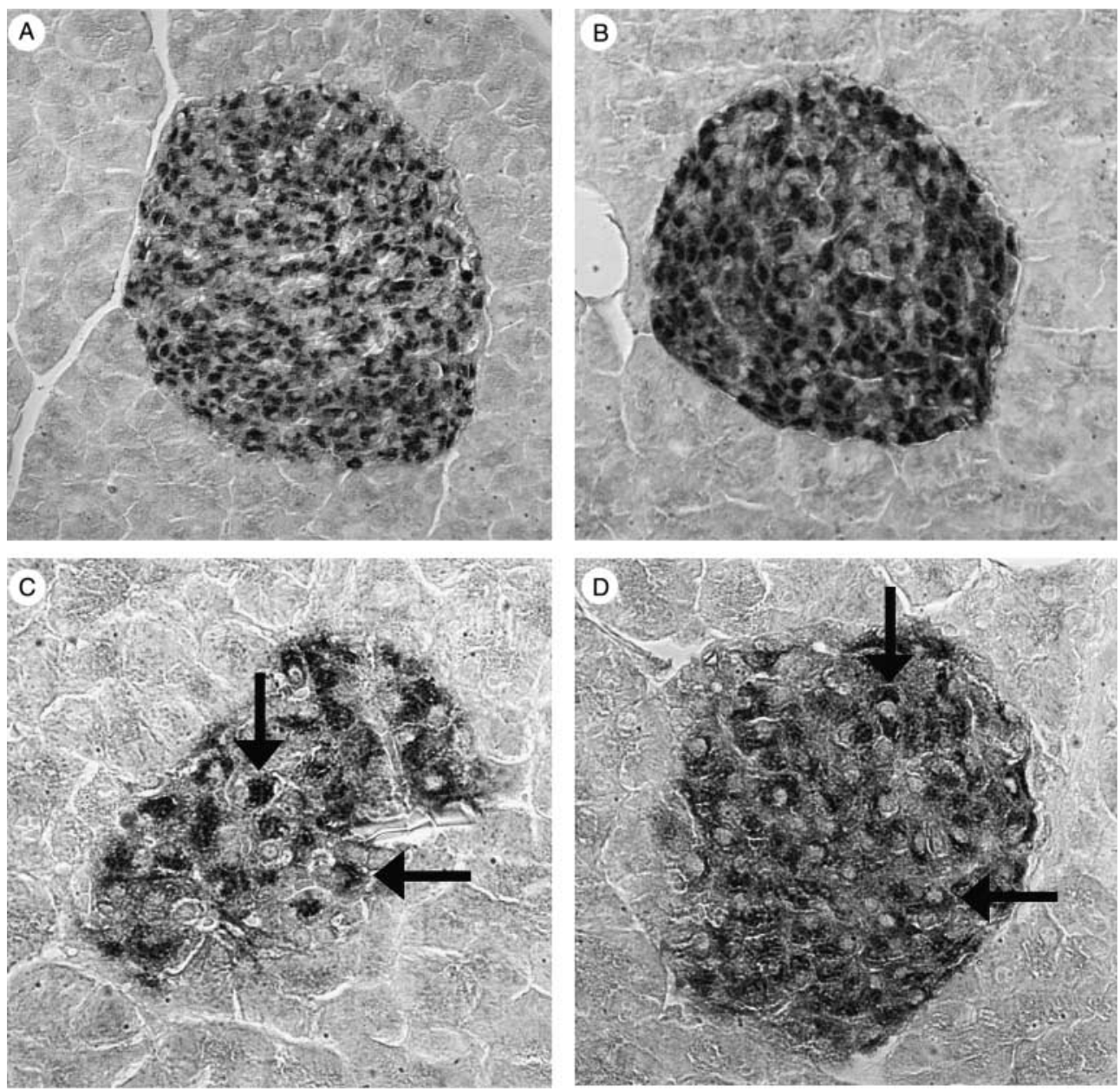

Figure 4 Cellular localization of hepcidin in rat pancreas. Immunohistochemical sections stained with $\mathrm{N}$ - and C-terminal hepcidin antibodies EG(2)-HepN (A and C) and EG(2)-HepC (B and D) showing immunoreactivity in insulin $\beta$-cells (arrows). (Magnification: $A, \times 200 ; B, \times 300, C$ and $D$, approximately $\times 400$ ).

in the pancreas is lower than that in the liver. Interpreting this critically, it has to be noticed that hepcidin in the pancreas is expressed exclusively in the islets of Langerhans, which constitute merely a small compartment of the total pancreatic parenchyma. Thus, the virtually lower expression level of hepcidin in the pancreas may roughly correspond to that in the liver. Consequently, the expression of hepcidin in the pancreas might gain additional importance in degenerative hepatic diseases with suspending production of hepcidin in the liver (e.g., liver cirrhosis).

In previous studies, hepcidin was localized in extra-hepatic key organs like the heart and the kidney (Kulaksiz et al. 2005, Merle et al. 2007, Sheikh et al. 2007), where it responds to an acute phase reaction. In the heart, hepcidin was localized at the intercalated disc area (Merle et al. 2007); in the kidney, hepcidin was expressed in the epithelial tubule and the duct cells and secreted into the urine (Kulaksiz et al. 2005). These data suggest a local role for hepcidin regulating the intrinsic iron homeostasis in these organs. In contrast, in the pancreas, hepcidin is localized in the endocrine cells secreting their products into the blood. Thus, the pancreas may contribute to the systemic hepcidin pool.

Using immunohistochemistry, hepcidin immunoreactivity was found thoroughly in the islets of Langerhans where the peptide was exclusively localized to pancreatic $\beta$-cells. Within these cells, immunoelectron microscopical studies revealed that hepcidin is confined to insulin-storing secretory granules assuming co-secretion of hepcidin and insulin upon the stimulation of pancreatic $\beta$-cells, e.g., by glucose. Indeed, we could detect hepcidin not only in the RINm5F cells (see below) but also in the supernatant of these cells measured by ELISA (Kulaksiz et al. unpublished data).

The co-localization of both peptides and their assumed co-release is in accordance with the recent findings demonstrating lowered C-peptide secretion (Fernandez-Real et al. 2002b) and hepcidin secretion (Nicolas et al. 2002, Abraham et al. 2006) after phlebotomy-induced iron depletion. Likewise, the reported relationship of body iron stores with serum insulin and blood glucose concentrations (Tuomainen et al. 1997, 

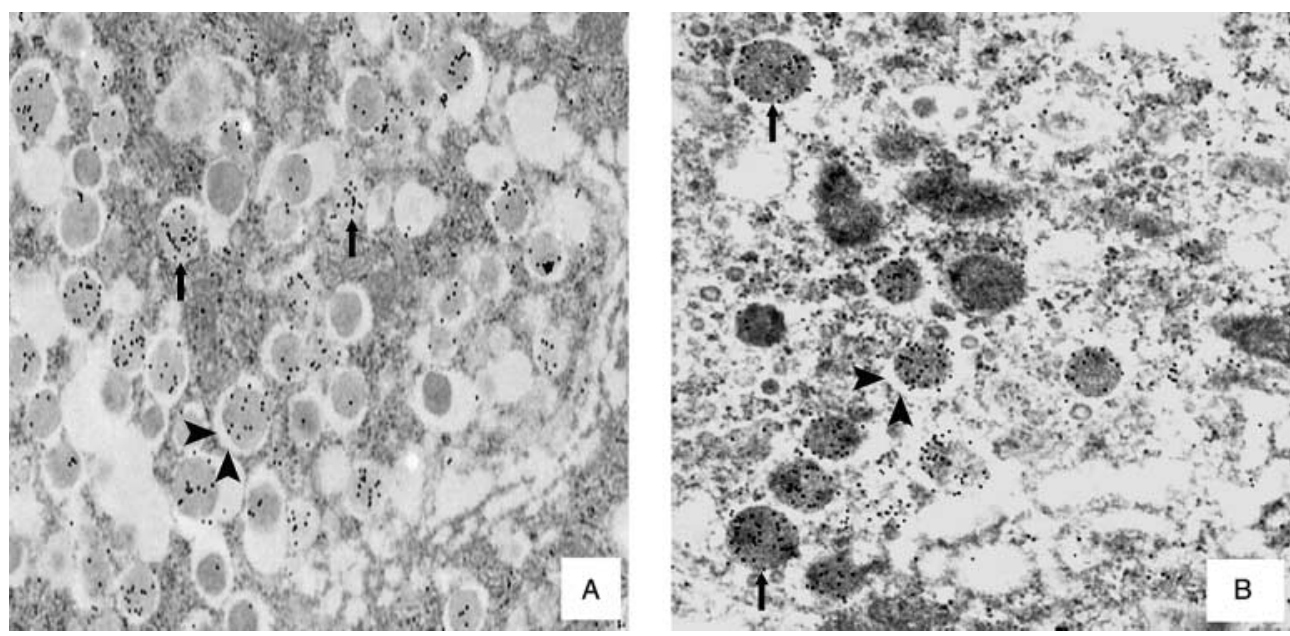

Figure 5 Subcellular localization of hepcidin in normal human (A) and rat (B) pancreatic $\beta$-cells by immunoelectron microscopy. Within the $\beta$-cells, hepcidin immunoreactivity is exclusively confined to the secretory granules. Immunoreactivity for this peptide is accumulated in the dense core of the secretory granules (arrows); the electron-lucent halo of these granules exhibits no immunoreactivity for hepcidin (arrowheads). Electron micrograph $(\times 25000)$.

Abraham et al. 2006) are clearly in line with the present data. Hence, the expression of hepcidin in pancreatic $\beta$-cells and its localization to insulin-storing secretory granules argues for an iron-regulatory function of the pancreatic $\beta$-cells beyond their proper glucose-regulatory function. Very likely, the regulation of iron and glucose metabolisms is distinctly coupled at least at the pancreatic level by the co-release of insulin and hepcidin. Even under pathophysiological conditions, the secretion of insulin and hepcidin seems to be linked since patients with hereditary hemochromatosis revealed not only a decreased insulin secretion (Abraham et al. 2006, McClain et al. 2006) but also decreased serum hepcidin levels (Bridle et al. 2003, Kulaksiz et al. 2004).

It is of particular importance that diseases of glucose metabolism such as diabetes mellitus are mostly associated with elevated body iron status, and diseases of iron overload are often accompanied by type 2 diabetes (Fernandez-Real et al. 2002a, Abraham et al. 2006). Phlebotomies, leading to decreased iron stores, reduce postprandial hyperinsulinemia (Facchini 1998, McClain et al. 2006) and improve insulin sensitivity (Hua et al. 2001). Moreover, frequent blood donations do not only decrease iron stores but also lead to reduced serum glucose values (Bofill et al. 1994). Consequently, a crosstalk between iron and glucose metabolisms has been suggested (Fernandez-Real et al. 2002a).

The pancreas is one of those organs mainly affected by hemochromatosis. Hemochromatosis is characterized by systemic iron overload that is due to duodenal hyperabsorption (Andrews 1999) together with symptoms of a high prevalence of abnormal glucose homeostasis secondary to decreased insulin secretion (Abraham et al. 2006, McClain et al. 2006). It is of particular note that iron deposition in islets is restricted to $\beta$-cells (Rahier et al. 1987) and that in hemochromatosis only the $\beta$-cells of the islets of Langerhans are affected by iron overload (Fig. 6). Furthermore, the (apo)ferritin content proved to be four- to eightfold higher in $\beta$-cells of rat islets treated with $20 \mathrm{mmol} / 1$
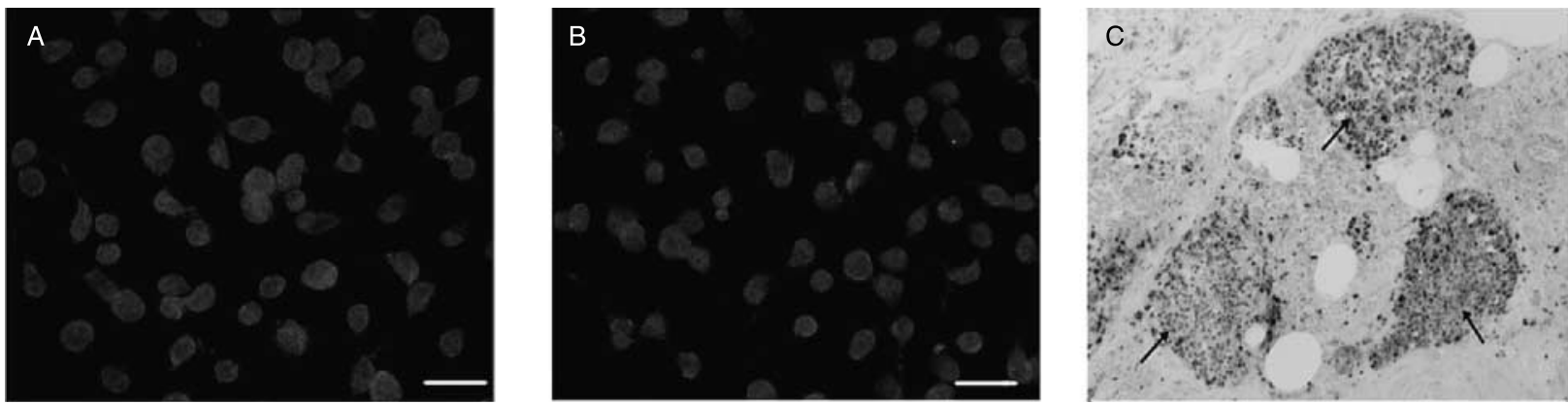

Figure 6 Cellular localization of hepcidin and iron in the pancreas. (A and B) Hepcidin expression in RINm5F cells with C- and N-terminal hepcidin antibodies EG(2)-HepC (A) and EG(2)-HepN (B) using immunofluorescence technique with Cy3. Scale bars, $5 \mu \mathrm{m}$. (C) Iron staining in pancreatic $\beta$-cells in a deceased patient with hereditary hemochromatosis $(\times 250)$. 

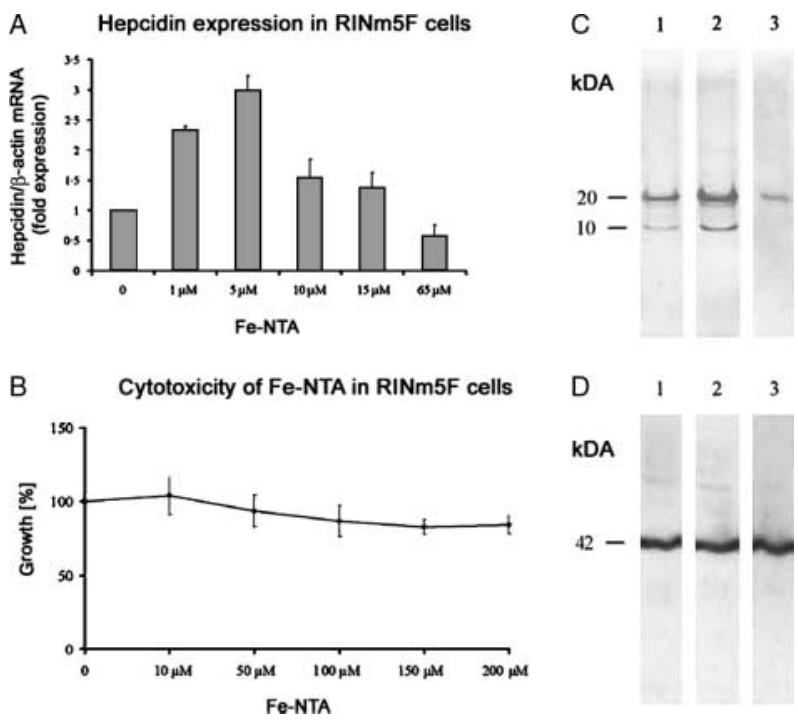

Figure 7 Hepcidin expression in $\beta$-cells regulated by iron. (A) Hepcidin expression in RINm5F cells after iron (Fe-NTA) stimulation using quantitative RT-PCR $(n=5)(1 \mu \mathrm{M}$ Fe-NTA, $P<0 \cdot 01 ; 5 \mu \mathrm{M}$ Fe-NTA, $P<0.001 ; 10 \mu \mathrm{M}$ Fe-NTA, $P<0.002 ; 15 \mu \mathrm{M}$ Fe-NTA, $P<0 \cdot 05$; $65 \mu \mathrm{M}$ Fe-NTA, $P<0 \cdot 05$ ). (B) Cytotoxicity of Fe-NTA in RINm5F cells measured by neutral red assay, 3 days after iron stimulation. Note that no cytotoxicity exists under the iron concentrations used. (C) Immunoblot analysis of iron-stimulated RINm5F cells showing hepcidin immunoreactivity at the range of $10 \mathrm{kDa}$. Note the up-regulation of hepcidin with $3 \mu \mathrm{M}$ Fe-NTA (2) and down-regulation with $65 \mu \mathrm{M}$ Fe-NTA (3) compared with control (1). The second immunoreactive band at $20 \mathrm{kDa}$ may reflect a dimeric type of hepcidin. (D) No up- or down-regulation was detected in $\beta$-actin expression under the same conditions.

glucose than that in $\beta$-cells treated with $1 \mathrm{mmol} / 1$ glucose (MacDonald et al. 1994), which unquestionably underlines the correlation between iron and glucose metabolism in these cells. Interestingly, in a recent study, no correlation between hepcidin and glucose homeostasis could be shown in the hepcidin knockout mouse (Ramey et al. 2007). However, in this study, iron overload was detected only in the acini and not in the $\beta$-cells. This could be due to interspecies differences. Indeed, in contrast to the human genome, the mouse genome contains two hepcidin genes encoding hepcidin and hepcidin 2; hepcidin is very weakly expressed in the mouse pancreas (Ilyin et al. 2003, Krijt et al. 2004).

Moreover, recent studies showed that pancreatic $\beta$-cells express the divalent metal ion transporter 1 (DMT1) (Koch et al. 2003), a protein of the duodenal epithelium crucially involved in cellular iron uptake (Hentze et al. 2004). The high levels of (apo)ferritin detected in the $\beta$-cells (MacDonald et al. 1994) may be explained by high iron fluxes through DMT1. Of note, we also could detect ferroportin, the only known mammalian iron exporter and hepcidin receptor (Nemeth et al. 2004), in $\beta$-cells (Kulaksiz et al. unpublished data). The presence of hepcidin and DMT1/ferroportin in pancreatic $\beta$-cells also argues for a local regulatory action in cellular iron transport.
In a set of cell stimulating experiments, we could show that the expression of hepcidin in $\beta$-cells is regulated by iron. Using quantitative RT-PCR and immunoblot assays, the regulatory effect of iron on hepcidin gene expression was demonstrated in RINm5F cells that represent a suitable model for $\beta$-cell experiments (Gazdar et al. 1980). The data obtained at the transcriptional and translational levels clearly show that increasing concentrations of iron result in a significant up-regulation (up to 221\%) of hepcidin-mRNA in a dosedependent manner. On the other hand, repeated experiments with iron concentrations of $65 \mu \mathrm{M}$ or higher clearly revealed a switch-over to down-regulation of hepcidin expression although the concentrations used did not prove to be cytotoxic. Similar effects of iron on hepcidin expression were also observed in HepG2 cells as already shown by us in previous studies (Gehrke et al. 2003, Fein et al. 2007). Likewise, an up-regulation of hepcidin expression in the liver was obtained after iron stimulation (Pigeon et al. 2001, Hentze et al. 2004, Montosi et al. 2005). Interestingly, in RINm5F cells and as already demonstrated in HepG2 cells (Gehrke et al. 2003) the expression of hepcidin decreased to the basal level when stimulating with higher amounts of iron. This could be clearly demonstrated at the mRNA and protein levels respectively. Hence, both cell lines of hepatic and pancreatic origin, i.e., HepG2 and RINm5F cells, equally react on iron; it may be suggested that the regulation of hepcidin expression is similar in the liver and in the endocrine pancreas.

In summary, hepcidin has been recognized as the key regulator of iron homeostasis (Hentze et al. 2004, Ganz 2005, Beutler 2006). Hitherto, the liver has been considered as the main site of hepcidin expression (Park et al. 2001, Kulaksiz et al. 2004). However, the present data clearly show that hepcidin is also expressed in the pancreas where the peptide is specifically attributed to the $\beta$-cells of the islets of Langerhans and confined to insulin-storing secretory granules. This assumes an additional iron-regulatory function of the pancreatic $\beta$-cells beyond their genuine function in the regulation of blood glucose.

In view of the fact that the pancreas belongs to those organs severely affected by hemochromatosis, the expression of the iron-regulatory peptide hepcidin in the pancreas opens up new vistas in the physiology of iron/glucose regulation and phenomenology of iron-storing diseases at the pancreatic $\beta$-cell level.

\section{Acknowledgements}

We thank Dr B Helmke (Institute of Pathology, University Hospital Heidelberg) for providing the iron-stained section of pancreas and Dr S Baltrusch (Hannover) for providing RINm5F cells. The technical assistance of S Braun and $\mathrm{K}$ Bents is greatly acknowledged. This study was supported by grant of the Deutsche Forschungsgemeinschaft (KU 1253/5-2). The authors declare that there is no conflict of interest that would prejudice the impartiality of this scientific work. 


\section{References}

Abraham D, Rogers J, Gault P, Kushner JP \& McClain DA 2006 Increased insulin secretory capacity but decreased insulin sensitivity after correction of iron overload by phlebotomy in hereditary haemochromatosis. Diabetologia $492546-2551$.

Andrews NC 1999 Disorders of iron metabolism. New England Journal of Medicine 341 1986-1995.

Beutler E 2006 Hemochromatosis: genetics and pathophysiology. Annual Review of Medicine 57 331-347.

Bofill C, Joven J, Bages J, Vilella E, Sans T, Cavalle P, Miralles R, Llobet J \& Camps J 1994 Response to repeated phlebotomies in patients with noninsulin-dependent diabetes mellitus. Metabolism 43 614-620.

Bridle KR, Frazer DM, Wilkins SJ, Dixon JL, Purdie DM, Crawford DH, Subramaniam VN, Powell LW, Anderson GJ \& Ramm GA 2003 Disrupted hepcidin regulation in HFE-associated haemochromatosis and the liver as a regulator of body iron homeostasis. Lancet 361 669-673.

Cetin Y, Aunis D, Bader MF, Galindo E, Jorns A, Bargsten G \& Grube D 1993 Chromostatin, a chromogranin A-derived bioactive peptide, is present in human pancreatic insulin (B) cells. PNAS 90 2360-2364.

Facchini FS 1998 Effect of phlebotomy on plasma glucose and insulin concentrations. Diabetes Care 212190.

Fein E, Merle U, Ehehalt R, Herrmann T \& Kulaksiz H 2007 Regulation of hepcidin in HepG2 and RINm5F cells. Peptides 28 951-957.

Fernandez-Real JM, Lopez-Bermejo A \& Ricart W 2002a Cross-talk between iron metabolism and diabetes. Diabetes 51 2348-2354.

Fernandez-Real JM, Pannaroja G, Castro A, Garcia-Bragado F, HernandezAguado I \& Ricart W $2002 b$ Blood letting in high-ferritin type 2 diabetes: effects on insulin sensitivity and $\beta$-cell function. Diabetes 51 1000-1004.

Ganz T 2005 Hepcidin - a regulator of intestinal iron absorption and iron recycling by macrophages. Best Practice \& Research. Clinical Haematology 18 171-182.

Gazdar AF, Chick WL, Oie HK, Sims HL, King DL, Weir GC \& Lauris V 1980 Continuous, clonal, insulin- and somatostatin-secreting cell lines established from a transplantable rat islet cell tumor. PNAS 77 3519-3523.

Gehrke SG, Kulaksiz H, Herrmann T, Riedel HD, Bents K, Veltkamp C \& Stremmel W 2003 Expression of hepcidin in hereditary hemochromatosis: evidence for a regulation in response to serum transferrin saturation and non-transferrin-bound iron. Blood 102 371-376.

Hentze MW, Muckenthaler MU \& Andrews NC 2004 Balancing acts: molecular control of mammalian iron metabolism. Cell 117 285-297.

Hua NW, Stoohs RA \& Facchini F 2001 Low iron status and enhanced insulin sensitivity in lacto-ovo vegetarians. British Journal of Nutrition 86 515-519.

Ilyin G, Courselaud B, Troadec MB, Pigeon C, Alizadeh M, Leroyer P, Brissot P \& Loréal O 2003 Comparative analysis of mouse hepcidin 1 and 2 genes: evidence for different patterns of expression and co-inducibility during iron overload. FEBS Letters $\mathbf{5 4 2} 22-26$.

Koch RO, Zoller H, Theuri I, Obrist P, Egg G, Strohmayer W, Vogel W \& Weiss G 2003 Distribution of DMT1 within the human glandular system. Histology and Histopathology 18 1095-1101.

Krause A, Neitz S, Magert HJ, Schulz A, Forssmann WG, Schulz-Knappe P \& Adermann K 2000 LEAP-1, a novel highly-disulfide bonded human peptide, exhibits antimicrobial activity. FEBS Letters 480 147-150.

Krijt J, Cmejla R, Sýkora V, Vokurka M, Vyoral D \& Necas E 2004 Different expression pattern of hepcidin genes in the liver and pancreas of C57BL/6N and DBA/2N mice. Journal of Hepatology 40 891-896.

Kulaksiz H, Schmid A, Honscheid M, Ramaswamy A \& Cetin Y 2002 Clara cell impact in air-side activation of CFTR in small pulmonary airways. PNAS 99 6796-6801.

Kulaksiz H, Gehrke SG, Janetzko A, Rost D, Bruckner T, Kallinowski B \& Stremmel W 2004 Pro-hepcidin: expression and cell specific localisation in the liver and its regulation in hereditary haemochromatosis, chronic renal insufficiency, and renal anaemia. Gut 53 735-743.
Kulaksiz H, Theilig F, Bachmann S, Gehrke SG, Rost D, Janetzko A, Cetin Y \& Stremmel W 2005 The iron regulatory peptide hormone hepcidin: expression and cellular localization in the mammalian kidney. Journal of Endocrinology 184 361-370.

MacDonald MJ, Cook JD, Epstein ML \& Flowers CH 1994 Large amount of (apo)ferritin in the pancreatic insulin cell and its stimulation by glucose. FASEB Journal 8 777-781.

McClain DA, Abraham D, Rogers J, Brady R, Gault P, Ajioka R \& Kushner JP 2006 High prevalence of abnormal glucose homeostasis secondary to decreased insulin secretion in individuals with hereditary haemochromatosis. Diabetologia 49 1661-1669.

Merle U, Fein E, Gehrke SG, Stremmel W \& Kulaksiz H 2007 The iron regulatory peptide hepcidin is expressed in the heart and regulated by hypoxia and inflammation. Endocrinology 148 2663-2668.

Montosi G, Corradini E, Garuti C, Barelli S, Recalcati S, Cairo G, Valli L, Pignatti E, Vecchi C, Ferrara F et al. 2005 Kupffer cells and macrophages are not required for hepatic hepcidin activation during iron overload. Hepatology 41 545-552.

Muckenthaler M, Roy CN, Custodio AO, Minana B, deGraafJ, Montross LK, Andrews NC \& Hentze MW 2003 Regulatory defects in liver and intestine implicate abnormal hepcidin and Cybrd1 expression in mouse hemochromatosis. Nature Genetics 34 102-107.

Nemeth E, Tuttle MS, Powelson J, Vaughn MB, Donovan A, Ward DM, Ganz T \& Kaplan J 2004 Hepcidin regulates cellular iron efflux by binding to ferroportin and inducing its internalization. Science 306 2090-2093.

Nicolas G, Chauvet C, Viatte L, Danan JL, Bigard X, Devaux I, Beaumont C, Kahn A \& Vaulont S 2002 The gene encoding the iron regulatory peptide hepcidin is regulated by anemia, hypoxia, and inflammation. Journal of Clinical Investigation 110 1037-1044.

Park CH, Valore EV, Waring AJ \& Ganz T 2001 Hepcidin, a urinary antimicrobial peptide synthesized in the liver. Journal of Biological Chemistry 276 7806-7810.

Pietrangelo A 2004 Hereditary hemochromatosis - a new look at an old disease. New England Journal of Medicine 350 2383-2390.

Pigeon C, Ilyin G, Courselaud B, Leroyer P, Turlin B, Brissot P \& Loréal O 2001 A new mouse liver-specific gene, encoding a protein homologous to human antimicrobial peptide hepcidin, is overexpressed during iron overload. Journal of Biological Chemistry 276 7811-7819.

Rahier JR, Loozen S, Goebbels RM \& Abrahem M 1987 The hemochromatotic human pancreas: a quantitative immunohistochemical and ultrastructural study. Diabetologia 30 5-12.

Ramey G, Faye A, Durel B, Viollet B \& Vaulont S 2007 Iron overload in Hepc1 (1/1) mice is not impairing glucose homeostasis. FEBS Letters $\mathbf{5 8 1}$ 1053-1057.

Roetto A, Papanikolaou G, Politou M, Alberti F, Girelli D, Christakis J, Loukopoulos D \& Camaschella C 2003 Mutant antimicrobial peptide hepcidin is associated with severe juvenile hemochromatosis. Nature Genetics 33 21-22.

Sheikh N, Dudas J \& Ramadori G 2007 Changes of gene expression of iron regulatory proteins during turpentine oil-induced acute-phase response in the rat. Laboratory Investigation 87 713-725.

Tuomainen TP, Nyyssonen K, Salonen R, Tervahauta A, Korpela H, Lakka T, Kaplan GA \& Salonen JT 1997 Body iron stores are associated with serum insulin and blood glucose concentrations. Diabetes Care 20 426-428.

Received in final form 28 January 2008

Accepted 4 March 2008

Made available online as an Accepted Preprint 4 March 2008 